\title{
A 36-year-old man with sudden severe headache
}

\author{
Paolo Simoni • Benoît Meunier • Manuel Deprez • \\ Tudor Racaru $\cdot$ Didier Martin
}

Received: 22 December 2010/Revised: 5 May 2011 /Accepted: 11 May 2011 /Published online: 3 June 2011

(C) ISS 2011

\section{Diagnosis}

Giant intradiploic epidermoid cyst. A large arachnoid cyst of the middle fossa of the brain is visible inferior to the intradiploic epidermoid cyst.

\section{Discussion}

Epidermoid cyst (EC) is a rare, benign, slow-growing lesion of the skull. The origin of ECs of the skull is debated. According to the congenital theory, ECs arise from ectodermic inclusions during neural tube closure (weeks 3-5 of embryogenesis). Epithelial cells become trapped in the bone by the laterally migrating otic or optic capsule [1-4].

Acquired ECs of the skull are believed to develop from inclusions of the epithelium after trauma $[1,2,5]$.

Epidermoid cysts of the skull are detected incidentally by imaging for other reasons [1].

The case presentation can be found at doi:10.1007/s00256-011-1206-3.

P. Simoni $(\bowtie) \cdot$ B. Meunier

Department of Diagnostic Imaging,

University Hospital of Liège (CHU) Domain du Sart Tilman,

Bat.35, 4000-B Liège, Belgium

e-mail: Paolo.Simoni@chu.ulg.ac.be

\section{Deprez}

Department of Pathology,

University Hospital of Liège (CHU) Domain du Sart Tilman,

Bat.35, 4000-B Liège, Belgium

T. Racaru $\cdot$ D. Martin

Department of Neurosurgery,

University Hospital of Liège (CHU) Domain du Sart Tilman,

Bat.35, 4000-B Liège, Belgium
Large ECs of the skull may become symptomatic, causing compression of the brain and neurological effects, including headache, seizures, optic nerve or venous sinus compression, and intracranial hypertension $[1,5,6]$. In our case, the cause of the patient's headache was nonspecific; it could have been attributed to direct meningeal irritation by the lesion or, less likely, to chronic changes in intracranial pressure, related to the mass.

Late complications of ECs include a fistulous tract that opens to the skin, suprainfections, and meningeal syndrome subsequent to cyst rupture [4, 7]. Rarely, intradiploic ECs undergo malignant transformation into squamous cell carcinoma [8].

On computed tomography (CT), ECs of the skull usually appear as well-defined, heterogeneous masses with densities ranging from -20 to +20 Hounsfield units (HUs), interspersed with higher-density areas that correspond to protein or cholesterol deposits (Fig. 1; see Test Yourself: Question) [9].

Epidermoid cysts typically have low signal intensity on T1-weighted MRI and high signal intensity on T2-weighted MRI. The T1-weighted MRI signal may increase focally, corresponding to cholesterol deposits (Fig. 2; see Test Yourself: Question) [1, 10].

Most ECs fail to show enhancement after injection of contrast media (Fig. 2) [10].

In our case, a large arachnoid cyst of the middle fossa was visible inferior to the EC.

The EC and CSF of the arachnoid cyst could not be differentiated based on the density by $\mathrm{CT}$ (the average density was approximately $12 \mathrm{HU}$ for both lesions; Fig. 1), whereas EC was easily detected by MRI (Fig. 2). ECs are heterogeneous and hyperintense relative to cerebrospinal fluid (CSF) on fluid attenuation inversion recovery (FLAIR) images (Fig. 2) [11]. Further, unlike arachnoid 
cysts, ECs do not restrict on diffusion-weighted imaging (DWI) and have similar apparent diffusion coefficients (ADCs) to brain parenchyma (Fig. 2) [12].

The differential diagnosis of EC of the skull includes other solitary lytic lesions, such as bone metastases, dermoid cysts, eosinophilic granulomas, meningioma, and solitary plasmacytomas. It is particularly common to misdiagnose EC as a dermoid cyst, the definitive diagnosis of which is primarily histological (Fig. 3). Nevertheless, ECs are typically off the midline, whereas dermoid tumors lie closer to the median sagittal plane [6].

Eosinophilic granulomas develop in infancy [13]. Local pain is the chief symptom, and the bone lesion is accompanied by a palpable tender mass that enhances after administration of contrast medium. At times, a button sequestrum is present within the osteolytic lesion, representing residual bone; the sequestrum can be seen better on CT [14].

Solitary plasmacytoma, meningioma, and bone metastases, unlike EC, have solid density on CT and enhance with administration of contrast media [15].
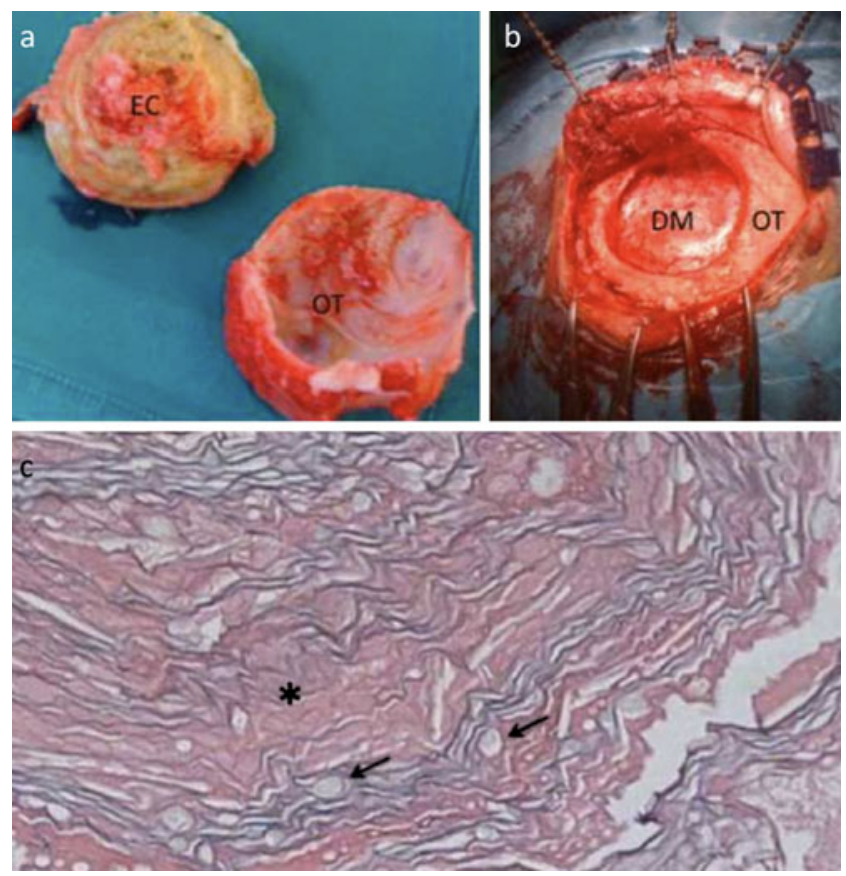

Fig. 3 a Gross anatomy, b surgical images, and c histological specimen (hematoxylin and eosin stain; magnification $\times 100$ ) of the epidermoid cyst. The surgical images show a thinned outer table $(O T)$, the epidermoid cyst $(E C)$ with no macroscopic appearance of the inner table, and an intact dura mater $(D M)$, demonstrating the intradiploic origin of the mass. These findings formally demonstrate the bony origin of the mass being the superficial layer of the dura mater, the skull's inner periosteum. According to the histology, there is amorphous material that contains keratin debris (asterisk) and cholesterol deposits (arrows), typical of an epidermoid cyst
Total removal of ECs is associated with a good longterm prognosis. If they are not removed completely, ECs can recidivate, recurring in $8.3 \%$ to $25.0 \%$ of surgical series cases [8].

In conclusion, intradiploic ECs of the skull are uncommon, but should be included in the differential diagnosis of solitary lytic lesions of the skull. In rare cases, a giant cyst can become symptomatic. MRI, including FLAIR and DWI sequences, is crucial for surgical planning, to detect complications and visualize surgical residuals.

\section{References}

1. Osborn AG, Preece MT. Intracranial cysts: radiologic-pathologic correlation and imaging approach. Radiology. 2006;239(3):650-64.

2. Zadek I, Cohen HG. Epidermoid cyst of the terminal phalanx of a finger: with a review of the literature. Am J Surg. 1953;85 (6):771-4.

3. Kalgutkar A, Kini S, Jambhekar N, Das S. Intradiploic primary epithelial inclusion cyst of the skull. Ann Diagn Pathol. 2006;10 (1):20-3.

4. Sargent EW, Garcia P, Paniello RC, Spector GJ. Giant intradiploic epidermoid cyst of greater sphenoid wing causing unilateral proptosis and optic nerve compression. Skull Base Surg. 1993;3 (2):55-9.

5. Green AJ, Roberts DR, Swanson RA. Post-traumatic epidermoid cyst presenting with headache. Neurology. 2005;64(9):1657.

6. Arana E, Latorre FF, Revert A, Menor F, Riesgo P, Liaño F, et al. Intradiploic epidermoid cysts. Neuroradiology. 1996;38(4):306-11.

7. White AK, Jenkins HA, Coker NJ. Intradiploic epidermoid cyst of the sphenoid wing. Arch Otolaryngol Head Neck Surg. 1987;113 (9):995-9.

8. Yanai Y, Tsuji R, Ohmori S, Tatara N, Kubota S, Nagashima C. Malignant change in an intradiploic epidermoid: report of a case and review of the literature. Neurosurgery. 1985;16(2):252-6.

9. Duan Z, Chu S, Ma Y, Zhang H, Zhu J. Giant intradiploic epidermoid cyst of the occipital bone. J Clin Neurosci. 2009;16 (11): 1478-80.

10. Timmer FA, Sluzewski M, Treskes M, van Rooij WJ, Teepen JL, Wijnalda D. Chemical analysis of an epidermoid cyst with unusual CT and MR characteristics. AJNR Am J Neuroradiol. 1998;19(6):1111-2.

11. Hakyemez B, Aksoy U, Yildiz H, Ergin N. Intracranial epidermoid cysts: diffusion-weighted, FLAIR and conventional MR findings. Eur J Radiol. 2005;54(2):214-20.

12. Yamaguchi S, Hirohata T, Sumida M, Arita K, Kurisu K. Intradiploic arachnoid cyst identified by diffusion-weighted magnetic resonance imaging - case report. Neurol Med Chir (Tokyo). 2002;42(3):137-9.

13. Yoon SH, Park S. A study of 77 cases of surgically excised scalp and skull masses in pediatric patients. Childs Nerv Syst. 2008;24 (4):459-65.

14. David R, Oria RA, Kumar R, Singleton EB, Lindell MM, Shirkhoda A, et al. Radiologic features of eosinophilic granuloma of bone. AJR Am J Roentgenol. 1989;153:1021-6.

15. Cerase A, Tarantino A, Gozzetti A, Muccio CF, Gennari P, Monti $\mathrm{L}$, et al. Intracranial involvement in plasmacytomas and multiple myeloma: a pictorial essay. Neuroradiology. 2008;50:665-74. 